Note

\title{
Validation of standards suitable for genome size estimation of fungi
}

\author{
Pedro Talhinhas $^{\mathrm{a}, *}$, Daniela Tavares ${ }^{\mathrm{b}}$, Ana Paula Ramos ${ }^{\mathrm{a}}$, Susana Gonçalves ${ }^{\mathrm{b}}$, João Loureiro ${ }^{\mathrm{b}}$ \\ a LEAF-Linking Landscape, Environment, Agriculture and Food, Instituto Superior de Agronomia, Universidade de Lisboa, Tapada da Ajuda, 1349-017 Lisboa, Portugal \\ b CFE-Centre for Functional Ecology, Department of Life Sciences, University of Coimbra, 3001-401 Coimbra, Portugal
}

\section{A R T I C L E I N F O}

\section{Keywords:}

Cenococcum geophilum

Colletotrichum acutatum

DNA standard

Flow Cytometry

Genome size

Inonotus hispidus

\begin{abstract}
A B S T R A C T
Genome size information is fundamental to genome sequencing and may also uncover genomic aspects of evolution. Flow Cytometry, the preferred method for genome size estimation, requires suitable standards. Here we validate Inonotus hispidus, Colletotrichum acutatum and Cenococcum geophilum (41, 68 and $203 \mathrm{Mbp}$ ), as standards for fungal genome size estimation.
\end{abstract}

Fungal genome sizes range from 2.19 Mbp, for the Microsporidia Encephalitozoon romaleae, to $3706 \mathrm{Mbp}$, for the Pezizales Jafnea semitosta (Egertová and Sochor, 2017). Also, genome sizes vary across fungal phylogeny: while groups such as the Saccharomycotina, the Taphrinomycotina and the Ustilagomycotina present average genome sizes ranging between 12 and $18 \mathrm{Mbp}$, groups such as the Jahnulales (120 Mbp), the Pezizales (125 Mbp), the Geastrales (176 Mbp), and the Pucciniales (429 Mbp) are among the orders with the largest genome sizes in Fungi (Talhinhas et al., 2015). In fact, genome size variation across fungi could reflect evolution (Spanu, 2012), and may even be a driver of evolution through polyploidy, chromosome transfer and the activity of transposable elements (Stukenbrock and Croll, 2014). Genome size information, either arising from genome sequencing initiatives or from direct genome size measurements, is available for ca. 2000 species, which still leaves many large gaps in phylogeny, in cases up to the class rank (Kullman et al., 2005). However, in an era of large expansion of the number of fungal genome sequencing initiatives, genome size information is fundamental for the appropriate choice of genome sequencing approaches. Flow cytometry is currently the method of choice for genome size estimation, including for fungi (D'Hondt et al., 2011). However, flow cytometry requires the use of suitable DNA standards representing nuclei from selected species with genome sizes that are within up to a $4-5 \times$ difference to the species under analysis (D'Hondt et al., 2011). In plants, a selection of species with contrasting genome sizes has been validated as DNA standards, ranging from $1.11 \mathrm{pg} / 2 \mathrm{C}$ (for Raphanus sativus 'Saxa') to $34.76 \mathrm{pg} / 2 \mathrm{C}$ (Allium cepa 'Alice') (Doležel et al., 1992). Tavares et al. (2014) used Raphanus sativus, Solanum lycopersicum 'Stupické' (1.96 pg/2C) and occasionally the host plant as standards to determine the genome size of
30 Pucciniales species (rust fungi), depicting very large genomes in this fungal group. Pires et al. (2016) also used a plant species, Arabidopsis thaliana 'Col- 0 ' $(0.32 \mathrm{pg} / 2 \mathrm{C})$ as standard to determine the genome size of the Ascomycota fungi clustering in the Colletotrichum gloeosporioides species complex, although this standard did not perform exceptionally well, presumably due to the endopolyploid nature of the plant's tissue. As such, the objective of this work was to define and validate DNA standards suitable for fungal genome size estimation, considering that the average fungal genome size is ca. $59 \mathrm{Mbp}$ and that $95 \%$ of the fungal species with known genome size cluster in the 10-200 Mbp range, for which those plant standards are inappropriate. With a haploid genome size of $203 \mathrm{Mbp}(0.208 \mathrm{pg} / 1 \mathrm{C})$ (Bourne et al., 2014), Cenococcum geophilum is among the $5 \%$ largest fungal genomes, but still in the proximity (less than $5 \times$ difference) from over $40 \%$ of fungal species (40-1000 Mbp), according to the values available at the Fungal Genome Size Database (Kullman et al., 2005). Because of this, along with its amenability for in vitro cultivation, this fungus was tested as standard to be used for genome size estimation of other fungi. Among the latter, another two fungal species, Colletotrichum acutatum and Inonotus hispidus were tested and further validated as standards in the 40-60 Mbp range, in order to cover for the species with lower genome sizes (10-100 Mbp).

Cenococcum geophilum is a cosmopolitan ectomycorrhizal fungal species found in forest ecosystems and belongs to the phylum Ascomycota, class Dothideomycetes and family Gloniaceae. Cenococcum geophilum isolate 844.1 was obtained from sclerotia in soil in Quercus ilex ssp. ballota woodlands in Portugal (Bourne et al., 2014). Colletotrichum acutatum is a widespread plant pathogen causing diseases known as anthracnose in several host plants and it belongs to the

\footnotetext{
* Corresponding author.

E-mail address: ptalhinhas@isa.ulisboa.pt (P. Talhinhas).
} 
phylum Ascomycota, class Sordariomycetes and family Glomerellaceae. Colletotrichum acutatum isolate PT812 was isolated from olive fruits exhibiting anthracnose symptoms in Portugal (Talhinhas et al., 2009) and validated as belonging to $C$. acutatum sensu strictu upon the revision of the C. acutatum species complex (Damm et al., 2012). Inonotus hispidus is a macrofungus, commonly known as shaggy bracket, that causes white rot mainly on trunks of broad-leaved trees and belongs to the phylum Basidiomycota, class Agaricomycetes and family Hymenochaetaceae. The isolate LPV629 of I. hispidus was used. Filamentous and yeast fungal species with known (or presumed) genome sizes ranging between 10 and $100 \mathrm{Mbp}$ were selected for validation of the three species as reference standards, including: Calonectria pseudonaviculata isolate LPV600 Curvularia lunata isolate AL654; "Cylindrocarpon"-like isolate Cy300; Exserohilum rostratum isolate CV676; Rhizoctonia sp. isolate LPV630; Saccharomyces cerevisiae isolate CP1969. Colletotrichum acutatum isolate PT812 and Inonotus hispidus isolate LPV629 were first treated as testers and subsequently as standards.

Fungal nuclei were isolated using the chopping procedure as described by Pires et al. (2016) in the presence of a nuclei isolation buffer optimised by Loureiro et al. (2007). Yeast nuclei were extracted using the protocol by Sabatinos and Forsburg (2009): cells in liquid Yeast Extract-Glucose culture were grown to an $\mathrm{OD}_{595}$ of 0.4 , diluted 3:7 with absolute ethanol, pelleted $5 \mathrm{~min}$ at $3000 \mathrm{~g}$, resuspended in $50 \mathrm{mM}$ sodium citrate, pelleted in the same conditions, resuspended and incubated for $2 \mathrm{~h}$ in $50 \mathrm{mM}$ sodium citrate containing $0.1 \mathrm{mg} \mathrm{mL}^{-1}$ RNase A. Nuclei obtained by either method were purified by filtration through a $30 \mu \mathrm{m}$ mesh, stained using propidium iodide (PI; Sigma-Aldrich) at $50 \mu \mathrm{g} \mathrm{mL}{ }^{-1}$ (Pires et al., 2016) and analysed using a CyFlow Space flow cytometer (Sysmex-Partec $\mathrm{GmbH}$ ) equipped with a $30 \mathrm{~mW}$ green solid-state laser emitting at $532 \mathrm{~nm}$ for optimal PI excitation. Flow cytometer quality assessment, data acquisition parameters (including gating strategies to improve the quality of the histogram) and data analysis were performed as described by Pires et al. (2016). At least six replicates were analysed for each species. The holoploid genome size in pg (1C, the DNA content of one non-replicated holoploid genome with the chromosome number $\mathrm{n}$, the most common nuclear state for fungi; sensu Greilhuber et al., 2005) was estimated using the following formula: genome size of the reference standard $\times$ (mean $\mathrm{G}_{1}$ fluorescence of sample nuclei/mean $G_{1}$ /fluorescence of reference standard). The genome size in Mbp was also calculated for all isolates using the factor $1 \mathrm{pg}=978 \mathrm{Mbp}$ (Doležel and Bartoš, 2005).

Flow cytometry analyses of Cenococcum geophilum, Colletotrichum acutatum and Inonotus hispidus nuclei reveal average coefficients of variation of $4.6,5.7$ and $6.4 \%$ respectively, i.e., they were on average below $10 \%$, which are considered adequate for fungal species (Bourne et al., 2014). Additionally, they show clear and unequivocal results with low background noise (Fig. 1). The genome size of $C$. acutatum isolate PT812 was determined by comparison with that of $C$. geophilum to be of $0.0689 \pm 0.000981 \mathrm{pg}$ per haploid nucleus. The size of $I$. hispidus isolate LPV629 genome was measured by comparison against $C$. geophilum and C. acutatum, originating values of $0.0422 \pm 0.00107 \mathrm{pg}$ and $0.0423 \pm 0.00109 \mathrm{pg}$, respectively, per haploid nucleus.

The co-analysis of nuclei from each of the selected fungal species and from either Cenococcum geophilum, Colletotrichum acutatum or Inonotus hispidus enabled the successful measurement of their genome sizes (Fig. 2), ranging from 0.0236 to $0.1003 \mathrm{pg}$. With genomes of 41, 68 and $203 \mathrm{Mbp}$, Inonotus hispidus, Colletotrichum acutatum and Cenococcum geophilum are less than $4 \times$ different from ca. $97 \%$ of all fungi with known genome size, thus presenting adequate sizes to be used as standards for fungal genome size measurement. In this work we showed that these fungi can be reliably used for genome size estimation of fungal species with varied genome sizes, complementing Doležel et al. (1992) set of plant standards, which already proved to be suitable for the estimation of the genome size of some fungal species. Still, according to Greilhuber et al. (2007), the sample and the reference materials should have biological similarities. In accordance with the same

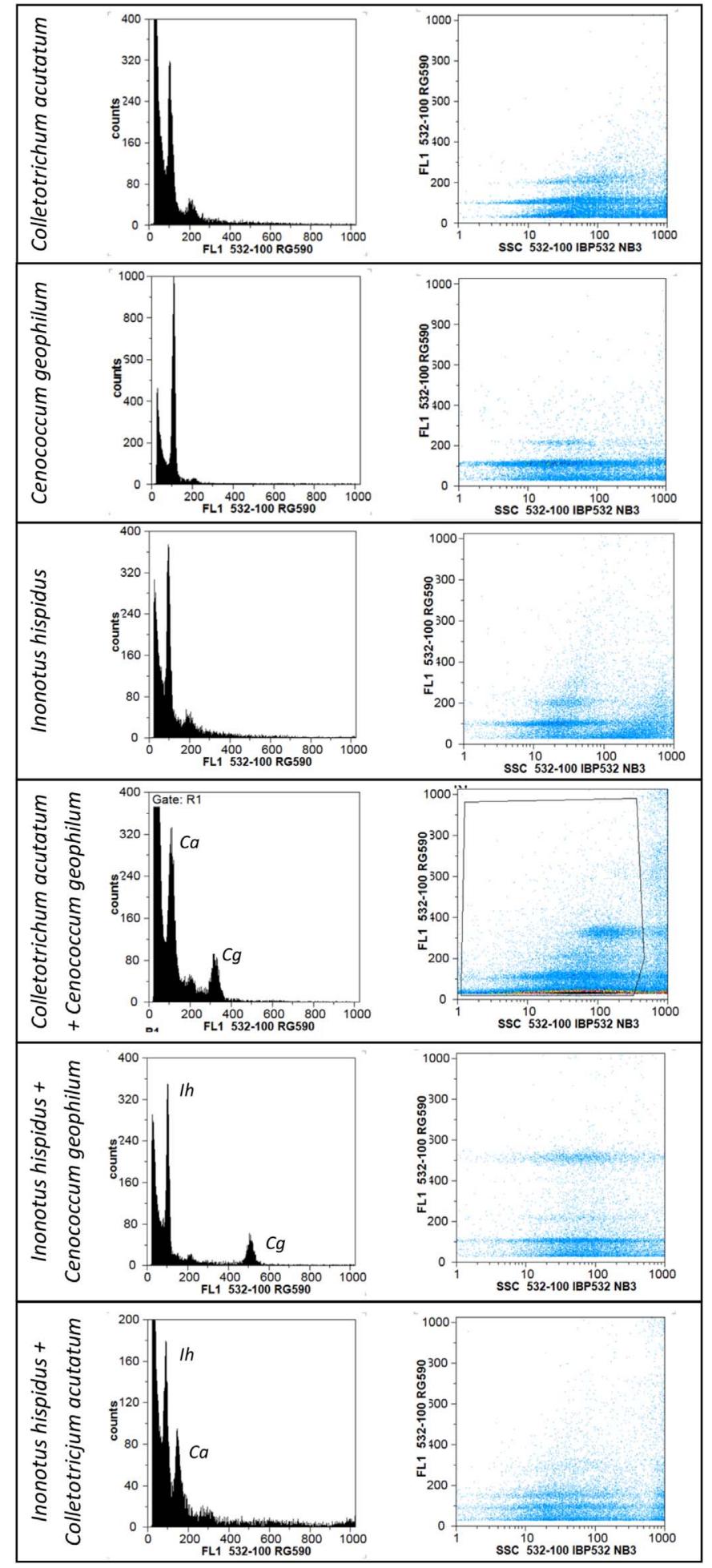

Fig. 1. Flow cytometric histogram of relative fluorescence intensities of propidium iodide-stained nuclei isolated from mycelium of Colletotrichum acutatum ( $\mathrm{Ca}$ ), Cenococcum geophilum $(C g)$ and/or Inonotus hispidus (Ih). In each panel, the image on the left represents the flow cytometric histogram of relative fluorescence intensities of propidium iodide-stained nuclei isolated from mycelium of the fungus under analysis (or simultaneously from mycelia of both fungi in the case of the three lower panels), and the image on the right represents the dot-plot of side light scatter (SSC) vs. fluorescence pulse integral in linear scale applying (when necessary) a gating region to exclude, as much as possible, partial nuclei and other types of debris in order to improve the quality of the histogram. 

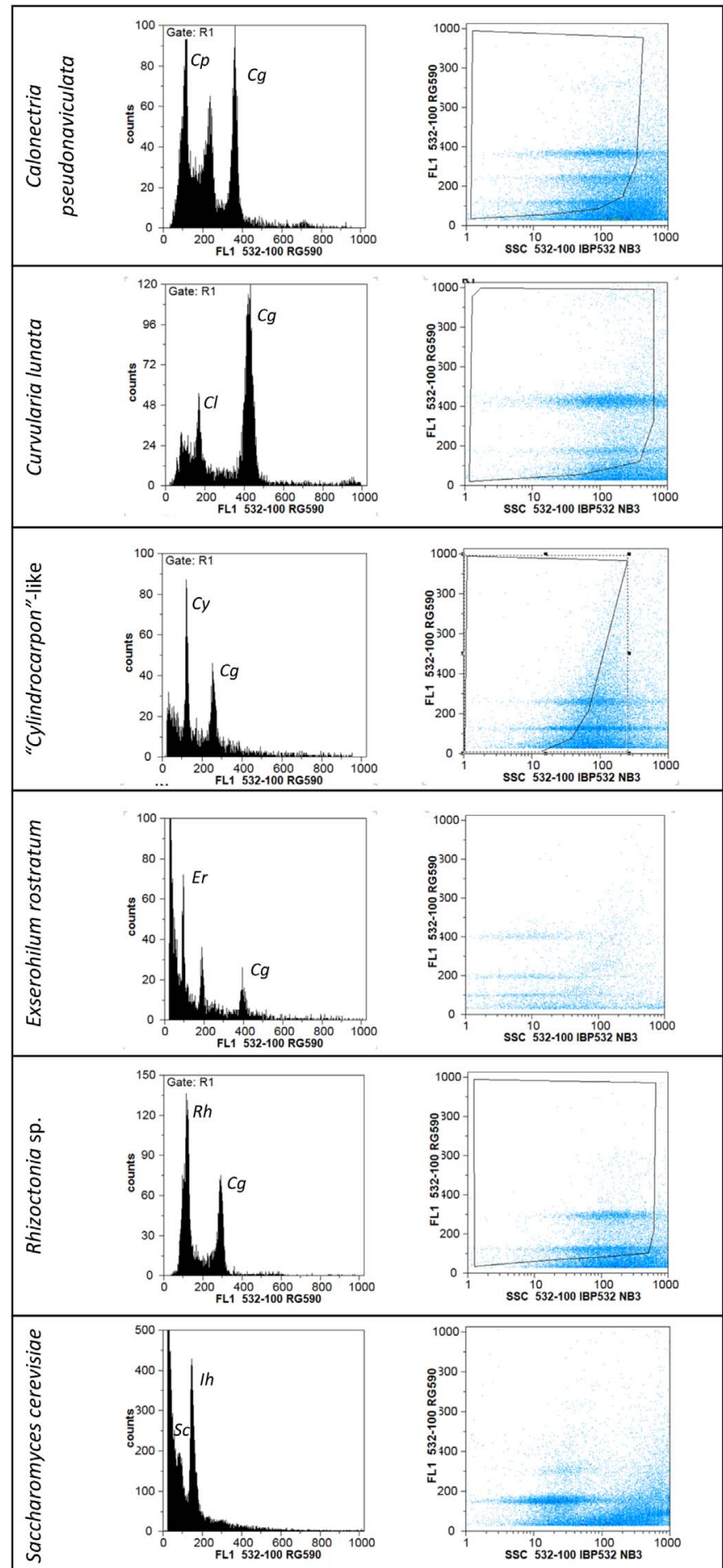

Fig. 2. Genome size measurement results for Calonectria pseudonaviculata ( $C p ; 0.0646 \mathrm{pg}$ / 1C), Curvularia lunata ( $\mathrm{Cl} ; 0.0411 \mathrm{pg} / 1 \mathrm{C})$, “Cylindrocarpon"-like (Cy; $0.1003 \mathrm{pg} / 1 \mathrm{C})$, Exserohilum rostratum (Er; $0.0505 \mathrm{pg} / 1 \mathrm{C}), \quad$ Rhizoctonia sp. $(R h ; 0.0864 \mathrm{pg} / 1 \mathrm{C})$, Saccharomyces cerevisiae $(S c ; 0.0236 \mathrm{pg} / 1 \mathrm{C})$ using flow cytometry. In each panel, the image on the left represents the flow cytometric histogram of relative fluorescence intensities of propidium iodide-stained nuclei simultaneously isolated from mycelium of the fungus under analysis and the DNA reference standard, Inonotus hispidus (Ih; $0.0422 \mathrm{pg}$ / 1C), Colletotrichum acutatum (Ca; $0.0689 \mathrm{pg} / 1 \mathrm{C}$ ), or Cenococcum geophilum (Cg; $0.208 \mathrm{pg}$ / 1C), and the image on the right represents the dot-plot of side light scatter (SSC) vs. fluorescence pulse integral in linear scale applying a gating region to exclude as much as possible partial nuclei and other types of debris in order to improve the quality of the histogram. authors, other criteria besides this one and the genome size (the most important one, as the standard species genome size must be different from the unknown sample, but not too different to avoid instrumental problems with linearity), are the availability and accessibility of the reference standards. These three fungi can be easily grown on standard culture media such as Potato Dextrose Agar. They were deposited in the culture collection of the Laboratório de Patologia Vegetal "Veríssimo de Almeida" (Instituto Superior de Agronomia, Universidade de Lisboa, Portugal) under references LPV652 for Cenococcum geophilum, LPV653 for Colletotrichum acutatum and LPV629 for Inonotus hispidus, and may be distributed upon request.

Fungal isolates used as testers in this study were kindly made available by Arlindo Lima, Catarina Prista and Teresa Nascimento (Instituto Superior de Agronomia, Universidade de Lisboa, Portugal). This research was supported by the Fundação para a Ciência e a Tecnologia (FCT), Portugal, concerning financial support to the research unit LEAF (UID/AGR/04129/2013) and to project PTDC/BIAMIC/171672014.

\section{References}

Bourne, E.C., Mina, D., Gonçalves, S.C., Loureiro, J., Freitas, H., Muller, L.A.H., 2014. Large and variable genome size unrelated to serpentine adaptation but supportive of cryptic sexuality in Cenococcum geophilum. Mycorrhiza 24, 13-20.

Damm, U., Cannon, P.F., Woudenberg, J.H.C., Crous, P.W., 2012. The Colletotrichum acutatum species complex. Stud. Mycol. 73, 37-113.

D'Hondt, L., Hofte, M., Van Bockstaele, E., Leus, L., 2011. Applications of flow cytometry in plant pathology for genome size determination, detection and physiological status. Mol. Plant Pathol. 12, 815-828.

Doležel, J., Bartoš, J.A.N., 2005. Plant DNA flow cytometry and estimation of nuclear genome size. Ann. Bot. 95, 99-110.

Doležel, J., Sgorbati, S., Lucretti, S., 1992. Comparison of three DNA fluorochromes for flow cytometric estimation of nuclear DNA content in plants. Physiol. Plant. 85, 625-631.

Egertová, Z., Sochor, M., 2017. The largest fungal genome discovered in Jafnea semitosta. Plant Syst. Evol. 303, 981-986.

Greilhuber, J., Doležel, J., Lysák, M.A., Bennett, M.D., 2005. The origin, evolution and proposed stabilization of the terms 'genome size' and 'C-value' to describe nuclear DNA contents. Ann. Bot. 95, 255-260.

Greilhuber, J., Temsch, E.M., Loureiro, J., 2007. Nuclear DNA content measurement. In: Doležel, J., Greilhuber, J., Suda, J. (Eds.), Flow Cytometry with Plant Cells: Analysis of Genes, Chromosomes and Genomes. Wiley-VCH Verlag GmbH \& Co. KGaA, Weinheim, pp. 67-101.

Kullman, B., Tamm, H., Kullman, K., 2005. Fungal genome size database. http://www. zbi.ee/fungal-genomesize/, Accessed date: 18 July 2017.

Loureiro, J., Rodriguez, E., Doležel, J., Santos, C., 2007. Two new nuclear isolation buffers for plant DNA flow cytometry: a test with 37 species. Ann. Bot. 100, 875-888.

Pires, A.S., Azinheira, H.G., Cabral, A., Tavares, S., Tavares, D., Castro, M., Várzea, V., Silva, M.C., Abranches, R., Loureiro, J., Talhinhas, P., 2016. Cytogenomic characterization of Colletotrichum kahawae, the causal agent of coffee berry disease, reveals diversity in minichromosome profiles and genome size expansion. Plant Pathol. 65, 968-977.

Sabatinos, S.A., Forsburg, S.L., 2009. Measuring DNA content by flow cytometry in fission yeast. Meth. Mol. Biol. 521, 449-461.

Spanu, P.D., 2012. The genomics of obligate (and nonobligate) biotrophs. Annu. Rev. Phytopathol. 50, 91-109.

Stukenbrock, E.H., Croll, D., 2014. The evolving fungal genome. Fung. Biol. Rev. 28, $1-12$.

Talhinhas, P., Neves-Martins, J., Oliveira, H., Sreenivasaprasad, S., 2009. The distinctive population structure of Colletotrichum species associated with olive anthracnose in the Algarve region of Portugal reflects a host-pathogen diversity hot spot. FEMS Microbiol. Lett. 296, 31-38.

Talhinhas, P., Ramos, A.P., Tavares, D., Tavares, S., Loureiro, J., 2015. Genome size estimates for six rust (Pucciniales) species. Rev. Ciênc. Agr. 38, 178-185.

Tavares, S., Ramos, A.P., Pires, A.S., Azinheira, H.G., Caldeirinha, P., Link, T., Abranches, R., Silva, M.C., Voegele, R.T., Loureiro, J., Talhinhas, P., 2014. Genome size analyses of Pucciniales reveal the largest fungal genomes. Front. Plant Sci. 5, 422. 